\title{
(Re)construindo aulas de Língua Portuguesa no diálogo entre universidade e escola
}

(Re)constructing Portuguese language classes in the dialogue between university and school

https://doi.org/10.34112/2317-0972a2018v36n74p77-90

\section{Eliane Aparecida Miquelettit ${ }^{1}$ \\ EDILAINE BUIN ${ }^{2}$}

Resumo: Apresentamos o relato de parte da experiência vivenciada durante o projeto de extensão "Leitura e escrita: possibilidades para a Educação Básica”, desenvolvido no âmbito das atividades do Programa Institucional de Bolsa de Iniciação à Docência (PIBID), na Faculdade de Artes, Comunicação e Letras (FACALE) da Universidade Federal da Grande Dourados (UFGD). O objetivo era oportunizar diálogos teóricos e práticos/metodológicos e a experimentação entre professores da educação básica, professores universitários e alunos do curso de Letras, sobre a leitura e a escrita de gêneros que fazem parte do cotidiano de ensino das escolas. Formação que possibilita a partilha e a ampliação dos conhecimentos dos envolvidos, ou seja, a formação inicial e continuada dos docentes. Relatamos como foi organizado o projeto, com destaque para as escolhas teóricas e metodológicas e abordamos o primeiro conteúdo desenvolvido no projeto, que envolveu o trabalho com a leitura de textos sincréticos.

PALAVRAS-CHAVE: Leitura; formação de professores; textos sincréticos.

ABSTRACT: The report presented in this study is part of the experience lived during the extension project "Reading and writing: possibilities for Basic Education", developed within the framework of the activities from the Institutional Scholarship Program (PIBID), located at the

1. Universidade Federal da Grande Dourados, Faculdade de Comunicação, Artes e Letras, Dourados, MS, Brasil.

2. Universidade Federal da Grande Dourados, Faculdade de Comunicação, Artes e Letras, Dourados, MS, Brasil. 
Faculty of Arts, Communication and Languages (FACALE) of Federal University of Grande Dourados (UFGD). The aim was to provide both theoretical and practical/methodological dialogues and experimentation among teachers from Basic Education, university professors and students from the Languages and Literature course, concerning the reading and writing of genres that compose the daily teaching of schools. A training that make possible both the sharing and expansion of the knowledge of those involved, that is, the initial and continuing training of teachers. Herewith, we report how the project was organized, with emphasis on the theoretical and methodological choices and we approached the first subject developed in the project, which involved the work with the reading of syncretic texts.

KEYWORDS: Reading; teacher training; syncretic texts.

Quem ensina aprende ao ensinar e quem aprende ensina ao aprender.

(FREIRE, 2002, p. 25)

\section{INTRODUÇÃO}

Neste texto, relatamos parte das experiências vivenciadas durante o desenvolvimento do projeto de extensão "Leitura e escrita: possibilidades para a Educação Básica", desenvolvido em 2017, no âmbito das atividades do subprojeto "Leitura, escrita e reescrita de gêneros discursivos: ações para o letramento", vinculado às atividades do Programa Institucional de Bolsa de Iniciação à Docência (doravante PIBID) ${ }^{3}$, na Faculdade de Comunicação, Letras e Artes (FACALE) da Universidade Federal da Grande Dourados (UFGD), subprojeto que, na ocasião, era coordenado $^{4}$ pelas autoras deste artigo. A reflexão em torno das experiências possibilita o aperfeiçoamento do próprio trabalho docente, nosso e de outros que, como nós, estão interessados em melhorar o nível de leitura e de escrita dos graduandos e professores atuantes no ensino básico e, indiretamente, atingir os estudantes atendidos por esse nível de ensino.

3. Agradecemos à CAPES pelo financiamento estendido ao Subprojeto de Letras (éramos 30 bolsistas de iniciação à docência (ID), 4 supervisores e 2 coordenadoras), às escolas parceiras do PIBID-Letras, Castro Alves, Capilé, Maria da Glória, Efantina e José Pereira Lins, que acolheram nossos projetos e trabalharam em parceria, às professoras colaboradoras no trabalho de formação, Alexandra Santos Pinheiro e Milenne Biasotto, e a todos, acadêmicos, mestrandos e professores, que voluntariamente participaram de nossas formações.

4. A função exercida neste caso era a de coordenadoras de área (CA), ou seja, gestoras do subprojeto PibidLetras/UFGD. 
Entendemos que o domínio de competências e habilidades de leitura/ interpretação e produção de textos nos mais diferentes gêneros discursivos (BAKHTIN, 2003) é essencial para que o aluno não só prossiga na sua carreira de formação acadêmica, mas, também, possa ser integrante ativo na sociedade da qual faz parte, exercendo, com qualidade, suas práticas discursivas como cidadão. Nesse sentido, promovemos a articulação de encontros de formação com o objetivo precípuo de oportunizarmos diálogos teóricos e práticos/metodológicos sobre a leitura e a escrita na escola, entre professores da educação básica (os professores de Língua Portuguesa atuantes nas escolas parceiras do Pibid-Letras, supervisores do programa ou não ${ }^{5}$ ), professores universitários (coordenadores do PIBID, do Programa de Educação Tutorial (PET) - e outros palestrantes convidados) e alunos do curso de Letras, sobretudo os envolvidos no PIBID e no PET do curso de Letras da UFGD. Propusemos uma formação na qual cada encontro era destinado ao estudo teórico e metodológico que pudesse ser finalizado com uma proposta de intervenção imediata nas escolas, pelos participantes.

A proposta foi pensada a partir do diagnóstico - obtido por nós, coordenadoras do PIBID, no trabalho realizado no ano de 2016 e início de 2017 - de dificuldade dos iniciantes à docência (ID) ${ }^{6}$, que tiveram como modelo a experiência nas escolas, predominantemente em aulas de gramática tradicional, para planejarem aulas envolvendo a leitura e a escrita. Nessa perspectiva, procuramos atender, entre outros, o seguinte objetivo do Programa: "contribuir para a articulação entre teoria e prática necessárias à formação dos docentes, elevando a qualidade das ações acadêmicas nos cursos de licenciatura" (BRASIL/CAPES, 2016). Nesse sentido, pretendíamos colaborar para a melhoria das práticas pedagógicas. $\mathrm{O}$ PIBID-Letras, nas edições de 2013 a 2018, teve a formação continuada como uma de suas principais ações, sempre planejada de acordo com as necessidades da comunidade - graduandos e professores da educação básica -, contando com a coordenação de professoras doutoras com larga experiência na Educação Básica7,

5. O professor supervisor do PIBID é o professor da escola de educação básica que orienta e viabiliza as atividades dos bolsistas de iniciação à docência na escola. Contávamos com 4 professores supervisores.

6. Nome dado aos graduandos bolsistas do PIBID; no subprojeto em foco contávamos com 30 deles.

7. Até dezembro de 2016, o subprojeto do PIBID Letras "Leitura, escrita e reescrita: ações para o letramento" contou com a coordenação das professoras Alexandra Santos Pinheiro e Edilaine Buin, ambas com experiência na Educação Básica: 7 e 16 anos respectivamente. A partir de dezembro de 2016, aquela deixou a coordenação, atuando como voluntária na formação. Assumiu a coordenação do PIBID-Letras, juntamente com Edilaine Buin, a professora Eliane Aparecida Miqueletti. O projeto, foco deste relato, foi o primeiro 
o que sempre facilitou, de modo mais natural, a conexão entre teoria e prática, fortalecendo os elos entre pesquisa, ensino e extensão.

Neste relato de experiência, vamos mencionar as atividades que compuseram um dos encontros de formação e que tiveram como foco central a leitura de textos sincréticos. A escolha tem em vista a falta desse tipo de abordagem nas escolas de Dourados a que nós autoras tivemos acesso, quer como docentes de Língua Portuguesa, quer por meio dos projetos de formação ministrados desde $2013^{8}$. Isso se soma ao fato da importância do olhar para a leitura multimodal, dada as necessidades do mundo contemporâneo, principalmente com a expansão dos textos compostos por imagem, som e escrita impulsionados pelas novas tecnologias da comunicação e da informação. Ainda que os textos sincréticos pareçam algo mais da atualidade, eles não são novidade e é possível encontrá-los, desde sempre, no nosso dia a dia, na escola, no cinema, no supermercado, andando pela rua.

No tópico a seguir, relatamos como foi o desenvolvimento de parte do projeto, tendo em vista o contexto político-educacional em que se inseriu. No tópico subsequente, descrevemos o trabalho com a leitura de textos sincréticos. Com base nisso, elaboramos as reflexões deste artigo para a formação continuada.

\section{Formação no Pibid: o desenvolvimento de um projeto de \\ LEITURA E ESCRITA EM TEMPOS TEMEROSOS}

A elaboração e a execução do projeto "Leitura e escrita: possibilidades para a Educação Básica” foram desenvolvidas em tempos “temerosos”, ano de mudanças políticas; entre elas, a Reforma do Ensino Médio e a retirada da literatura como disciplina do currículo do Ensino Médio, na grade de lotação do Mato Grosso do Sul, passando a integrar e dividir espaço com a Língua Portuguesa. Ainda que entendamos que é possível articular ambas em um mesmo trabalho com as várias linguagens, essa alteração trouxe a diminuição da carga horária destinada ao ensino de língua materna, o que, consequentemente, implicou a diminuição do

projeto de formação que contou com a elaboração da professora Eliane, que também chegava ao PIBID com a bagagem de experiências da Educação Básica, na qual trabalhou por 10 anos, vindo a somar aos trabalhos conhecimentos teóricos da semiótica para a leitura de textos sincréticos (textos que integram mais de uma linguagem na construção dos sentidos), os quais pretendia aplicar para o ensino básico.

8. A professora Eliane Aparecida Miqueletti exerceu a docência em escolas públicas de Dourados entre $2005 \mathrm{e}$ 2016. Edilaine Buin iniciou seu contato nas escolas em Dourados em 2013 como ministrante e coordenadora de diversos projetos de extensão. 
espaço real para a literatura, nem sempre acolhida pelos professores, que, costumeiramente, trabalham com aspectos mais voltados para o estudo da gramática tradicional e/ou da escrita.

A convivência com os docentes da educação básica possibilitou o contato com as dificuldades em integrar a literatura aos estudos da linguagem, tanto no Ensino Fundamental II quanto no Ensino Médio. Nossa participação no encontro na Câmara Municipal de Dourados, promovido pelo movimento "Por um MS literário", em março de 2017, que colocou em pauta os prejuízos com o fim da disciplina específica de literatura e a diminuição da carga horária geral ${ }^{9}$, reforçou a necessidade urgente de elaborarmos uma formação focada na integração e na articulação entre literatura e análise linguística, com vistas ao fortalecimento das habilidades de leitura/interpretação e produção de textos.

Diante desse contexto, organizamos o projeto em oficinas de formação, ministradas semanalmente (totalizando $48 \mathrm{~h} /$ aula presenciais), divididas em dois principais eixos, envolvendo, principalmente, a leitura e a escrita: o eixo da Leitura/Literatura e o eixo da Escrita/Reescrita. Buscamos, no primeiro momento, apresentar uma proposta de trabalho relacionando teoria e prática; logo na sequência, abríamos para a avaliação do grupo e relato de vivências sobre as temáticas trabalhadas. Além disso, cada ministrante ${ }^{10}$, ao longo de suas oficinas, desenvolvia uma atividade diagnóstico-avaliativa com todos os participantes: leitura interpretativa de livro e capa ou análise de texto sincrético, construção de perguntas/propostas didáticas, produção de crônica argumentativa, prática de tipos de correção de texto.

O quadro de conteúdos programáticos foi organizado em três blocos com enfoques entre: leitura, escrita e articulação entre língua e literatura ${ }^{11}$ :

9. No Estado do Mato Grosso do Sul, as escolas públicas contavam, no Ensino Médio, com 4 aulas de Língua Portuguesa e 2 de Literatura. Com a alteração, foi extinta a disciplina Literatura, e Língua Portuguesa passou a ter 5 aulas.

10. As ministrantes foram, além das autoras deste artigo, as professoras Alexandra Santos Pinheiro e Milenne Biasotto, às quais agradecemos a parceria. A professora Alexandra ficou, juntamente com a professora Eliane Aparecida Miqueletti, responsável pelo eixo Leitura/Literatura; a professora Milenne, juntamente com a professora Edilaine Buin, pelo eixo Escrita/Reescrita.

11. Ao conceito de "língua" integramos discussões voltadas para a análise linguística e a produção textual; ao de "literatura", aspectos relacionados à leitura de textos literários na escola. No terceiro bloco de conteúdos, procuramos articular as três principais competências envolvidas nas aulas de Língua Portuguesa: leitura, escrita e análise linguística. Verificamos certa carência em relação à abordagem da análise linguística e programávamos aprofundar essa questão, mas com a interrupção do Programa, no início de 2018, isso não foi possível. 


\begin{tabular}{l} 
1. O que é leitura? Leitura de textos sincréticos na escola. \\
2. A leitura literária na escola. \\
3. Texto literário e ensino de língua portuguesa. \\
4. Uma proposta para a leitura no Ensino Fundamental II. \\
5. Metodologias para o ensino de leitura na escola. \\
\hline 6. A escrita a partir de gêneros. \\
7. Atividades práticas de escrita/ reescrita textual I. \\
8. Atividades práticas de escrita/ reescrita textual II. \\
\hline 9. Língua e Literatura: possibilidades para o ensino básico. \\
10. Língua e Literatura: possibilidades para o ensino básico. \\
11. Uma aula para o ensino de leitura I. \\
12. Uma aula para o ensino de leitura II.
\end{tabular}

Quadro 1- Quadro de conteúdos programáticos - Fonte: As autoras.

Para o exercício de aplicação dos conhecimentos que desenvolvíamos na formação e como forma de avaliar nosso trabalho, intermediamos as oficinas com a apresentação de mini-aulas realizadas pelos IDs e pelos petianos, o que ocorreu nos itens $4,7,8$, 11 e 12 apresentados no quadro. Alguns participantes, aleatoriamente escolhidos, formando duplas ou trios, deveriam utilizar os conhecimentos adquiridos nas oficinas até então ministradas, planejar uma aula e apresentar na formação, na forma de uma simulação de aula para a Educação Básica. Após a apresentação, fazíamos, em conjunto, a avaliação.

Esses momentos de desenvolvimento de aulas inspiradas e planejadas com base nos conteúdos, em nossa perspectiva, foram os mais produtivos ao longo da formação. Constituíram espaço para a partilha efetiva entre docentes, tanto os universitários quanto os da educação básica, e docentes em formação, o que possibilitou crescimento conjunto. Situações que, algumas vezes, nos fizeram repensar nas colocações de Paulo Freire (2000, p. 30) sobre a relação entre aluno e professor na sala de aula. No nosso caso, a relação entre professores formadores e em formação, envolvendo:

[...] uma prática pedagógica participativa, dialógica e democrática, [...] na qual é essencial que o professor possa ajudar o aluno a reconhecer-se como construtor de seu conhecimento, e que é a partir desse (re)- conhecimento que aprendente e ensinante 
podem se conectar para um estabelecimento de relações que venham contribuir para um avanço no processo de desenvolvimento para a aprendizagem.

Os participantes da formação, nessas ocasiões, colocavam-se em ação, a começar pelo planejamento de aulas que integrassem leitura, escrita e análise linguística/ estudo da língua, bem como a execução destas, em simulação de uma situação de aula, diante de uma plateia que, antes de ser o simulacro do ensino básico, era real e crítica. Os holofotes deslocavam-se dos ministrantes responsáveis pelas oficinas para os professores em formação e/ou formados, os quais contavam com as críticas positivas e negativas na sequência de suas exposições. Essa participação ativa possibilita que todos os envolvidos se situem como construtores do próprio conhecimento e o de seus parceiros, processo democrático tão defendido por Paulo Freire.

As oficinas deram suporte para a preparação conjunta de aulas para o ensino básico, uma vez que apresentaram abordagens didáticas às vezes diversas daquelas que a comunidade em foco encontra nas escolas públicas (e até mesmo privadas) pelas quais circula. Os encontros de formação deram oportunidade para que estas aulas fossem desenvolvidas a partir de um exercício de simulação da sala de aula da escola básica.

De maneira geral, o eixo da Escrita/Reescrita foi desenvolvido partindo do princípio de que a efetivação do trabalho, com qualidade, necessita de tempo para as fases de planejamento, escrita e reescrita, constituindo-se em um processo de avaliação contínua da própria produção, tanto por parte do professor/corretor, quanto do aluno/produtor, o que demandará atenção especial para a reescrita, ação que estimula a atividade epilinguística da linguagem, ou seja, a reflexão sobre a própria construção linguística, sobre a língua.

Para se ensinar a escrever é fundamental também ser um escrevente. Nesse sentido, trabalhamos esse eixo envolvendo os participantes na escrita do gênero crônica argumentativa, gênero escolhido por ser um dos pedidos nos últimos vestibulares da UFGD e comentado, no âmbito da escola, como um gênero difícil para a produção. Todos foram convidados a participar do processo de entendimento do gênero, da produção, correção e reescrita, vivenciando o processo na prática e, dessa forma, podendo sentir parte das dificuldades enfrentadas pelos alunos da educação básica. Isso foi muito produtivo, gerando comentários, entre outros, como: "nossa, não sabia que era tão difícil escrever uma crônica argumentativa!”. Ainda nesse eixo, oportunizamos momentos para refletir sobre os tipos de correção, utilizando autores como Ruiz (2001), Guedes (2002), Buin (2002, 2013), Buin \& Biasotto (2016). 
Em relação ao eixo Leitura/Literatura, planejamos os encontros tendo em vista que o professor, como mediador, deve, para além de gostar de ler, saber ler, ou seja, atribuir sentido para o que lê; por isso a importância primordial da sua formação. A leitura requer competências de dimensões linguísticas, discursivas, ideológicas, afetivas, históricas. Implicados nisso, autor e leitor "não são pura individualidade", como destaca Lajolo, mas são "[...] atravessados por todos os lados da história: pela história coletiva que cada um vive no momento respectivo da leitura e da escrita, e pela história individual de cada um; é na interseção destas histórias, aliás, que se plasma a função autor e leitor" (2009, p. 104), e é papel da escola fazer com que o aluno tome consciência disso. Na medida do possível, envolvidos no contexto de retirada da literatura como disciplina do currículo do Ensino Médio, procuramos, por exemplo, construir possibilidades para trabalhar textos literários articulados aos outros conteúdos de Língua Portuguesa.

Conforme anunciamos anteriormente, no próximo tópico, apresentamos as atividades desenvolvidas em uma das oficinas da formação, que, como as outras, deram suporte para seus participantes planejarem outros modelos de aulas envolvendo leitura/literatura e ensino de Língua Portuguesa. Focamos aqui, pelos motivos já postos, no modelo que envolve a multimodalidade, a oficina do primeiro item do conteúdo programático: "O que é leitura? Leitura de textos sincréticos na escola".

\section{Leitura de textos SinCRÉticos Na FormaÇão de PROFESSORES}

Nosso objetivo era iniciar a reflexão sobre a leitura dos mais variados gêneros discursivos, entre eles, aqueles compostos por textos sincréticos. Esses, seguindo a terminologia da semiótica francesa, integram as composições textuais que gerenciam mais de uma linguagem (a verbal, parte escrita, e a não-verbal, como imagens, por exemplo) na construção do sentido, como explica Discini (2005, p. 57): "no plano de conteúdo estão as vozes em diálogo, está o discurso. No plano da expressão está a manifestação do sentido imanente, feita por meio da linguagem sincrética, que integra o visual e o verbal sob uma única enunciação”.

Para isso, iniciamos o encontro dispondo textos de diferentes gêneros e suportes sobre uma mesa para que os participantes escolhessem um deles. Logo depois, pedimos para que falassem o motivo que os levou a escolher aquele texto. Entre as justificativas estavam: "a imagem chamou minha atenção", "gosto desse tipo de texto", "já conhecia esse conto e gosto dele", "gostei do título". Na sequência, a problematização 
foi realizada com os seguintes questionamentos: o que é leitura? Quem são os incentivadores da leitura? Existe a leitura certa/errada? O que faz de nós bons leitores? O que envolve a leitura? Quais competências você utiliza para ler um texto? Para responder a essas questões, em conjunto, apresentamos algumas considerações apoiadas pela seguinte base teórica: PCN de Língua Portuguesa (1998), Lajolo (1982; 2009), Freire (2002; 2005), Rojo (2009; 2012), Antunes (2003), Santos; Riche; Teixeira (2015).

Nessa perspectiva, as discussões mais intensas foram em torno da afirmativa de que o professor, primeiro, precisa gostar de ler e ser um bom leitor, para, então, levar os estudantes para boas experiências de leitura. E, tendo em vista que as competências para ler implicam conhecimentos prévios, a escola deve proporcionar atividades de leitura de diferentes textos, de forma que não sejam utilizados como pretexto para o ensino gramatical ou para a produção escrita. Dentro disso, discutimos os "equívocos" que desestimulam o trabalho com a leitura na escola, entre eles, atividades que estão centradas na decodificação, que não apresentam função, são puramente escolares e se limitam a recuperar elementos explícitos. Reforçamos, assim, que a leitura deve ampliar os repertórios de informação e favorecer a experiência do prazer estético. Pedagogicamente, isso implica o uso de textos autênticos e, na medida do possível, inteiros (não trechos, como muitas vezes ainda presenciamos nas escolas), o que auxilia a leitura interativa, motivada, crítica, em síntese, a reconstrução do texto nunca desvinculada do sentido (ANTUNES, 2003).

Após esse preâmbulo, passamos então para a análise de textos sincréticos, mostrando que todo texto é o resultado de uma construção que sofre influência da interação, ou seja, das formações ideológicas envolvidas - as escolhas realizadas para a manifestação do conteúdo não são aleatórias. Apresentamos a análise de capas de revista, de quadros, de propagandas e destacamos a importância das escolhas e da articulação entre as linguagens. Nos comentários, verificamos que a maioria apresentava dificuldades: demoravam a perceber a relação entre cores, formas, disposição das imagens e relação com o verbal na construção dos sentidos.

Por fim, para refletirmos sobre etapas e estratégias de leitura na escola, apresentamos a proposta que Santos, Riche e Teixeira (2015) utilizam, retomando Silva (1992), o que envolve, nas atividades para leitura, três principais momentos: atividades pré-textuais (perguntas/análises motivacionais, ativando conhecimentos prévios e hipóteses iniciais, como a análise da capa de um livro), atividades textuais (perguntas/análises textuais e linguísticas, incluindo, por exemplo, inferências) e atividades pós-textuais (continuação da análise, relações contextuais, motivação para outras leituras). 
Simulamos uma aula de leitura que se resumia na apresentação da obra literária Indez, de Bartolomeu Campos Queiroz, edição de 1999. O encontro foi ministrado pela professora Eliane Aparecida Miqueletti, uma das autoras deste artigo, que trabalhou com a construção da capa do livro. Inicialmente, ela apresentou-o sem o título, direcionando a leitura apenas da linguagem não-verbal. A capa é composta pela imagem, delimitada em um enquadramento, composta por quatro galinhas, cada uma de uma cor, dispostas sobre um gramado e sob um céu azul, entrecortado por um risco na diagonal, de múltiplas cores, lembrando um arco-íris. Segue imagem da capa utilizada:

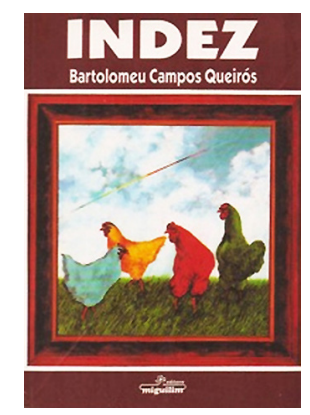

Imagem 1: capa do livro Indez. Fonte: Queiroz (1999).

A partir da leitura inicial, os participantes puderam sugerir temáticas: "história de um galinheiro", "algo sobre um sítio". Na sequência, a revelação da capa inteira, com título e nome do autor, causou estranheza de parte considerável dos participantes: Bartolomeu Campos Queiroz não era um autor conhecido por todos. Foi preciso trazer algumas informações sobre ele. "Indez" também não era uma palavra conhecida pela maioria. Depois de poucos minutos, apenas alguns supervisores e alunos, que moram ou moraram na zona rural, souberam relacionar o nome ao ovo que se coloca no lugar em que se quer que a galinha faça a postura. E qual a relação da composição dessa capa com a história presente neste livro? Eis a grande questão que só poderia ser desvendada com a leitura de toda a narrativa. Terminamos com a leitura das páginas iniciais da obra. Entre os presentes, apenas três conheciam a história e os outros estavam curiosos por conhecer ${ }^{12}$.

12. Não é objetivo desse artigo apresentar a análise da capa do livro trabalhado no encontro, mas destacamos que ela possui relação direta e metafórica com a narrativa poética, a história de um menino do campo, Antônio, 
Ao final do encontro, encaminhamos as seguintes atividades, para que os participantes escolhessem apenas uma delas:

$1^{\text {a }}$ opção: escolha um texto sincrético (textos que articulam mais de uma linguagem para construir um sentido: propagandas, música, capa de revista) e elabore questões que poderiam servir para trabalhar com este texto na escola - poderá seguir a proposta de sequência de atividades proposta por Santos, Riche e Teixeira (2015).

$2^{\mathrm{a}}$ opção: leia o livro Indez, de Bartolomeu Campos Queirós, e explique/analise o sentido da capa do livro; qual a sua relação com a narrativa lida?

As opções propiciaram a ação dos participantes. Na primeira opção, ao invés de responderem a perguntas prontas, eles tiveram que elaborá-las, o que exige maior reflexão e posicionamento como mediadores de leitura. $\mathrm{O}$ trabalho envolveu a leitura - de textos literários ou não, as várias linguagens, não só a escrita - conectada aos outros conteúdos de língua portuguesa. Na segunda opção, os participantes puderam exercitar a leitura proposta no encontro.

Ao longo do desenvolvimento da oficina, notamos a participação efetiva dos graduandos e professores. Alguns relataram gostar do trabalho relacionando linguagem verbal e não-verbal, mas que tinham dificuldades para "enxergar algumas coisas". Em um dos cadernos de campo, um dos instrumentos formativos e avaliativos utilizado pelo PIBID-Letras para o registro (relato e reflexão) de todas as atividades realizadas no projeto, uma das alunas escreveu: "terminei a tarde de formação com vontade de ler o livro de Bartolomeu Campos Queirós e estimulada a investir em estudos mais profundos do texto. Aprendi que sempre há como fazer de qualquer texto um vasto estudo". Da imagem da capa do livro veio a análise dos recursos linguísticos, momento da pré-leitura, que despertou a vontade de ler. Relatos assim

que trata da temática da "infância”. O menino vem ao mundo prematuramente, tem saúde frágil e revelase sensível à vida, possui profunda capacidade de contemplação. "INDEZ”, que também aparece na obra com o seu sentido denotativo (ovo chamariz), é o próprio local de origem em que está o protagonista, é a representação da infância, suscetível e delicada. A galinha é uma das figuras que estão presentes em vários momentos da história. Em um deles, a mãe brinca com os filhos ao tingir as galinhas com as cores do arco-íris, criando condições para o encantamento. Em síntese, uma das leituras possíveis para a capa é o enquadramento desse momento, exemplo entre muitos que compõem a obra e que misturam realidade e fantasia/imaginação, atmosfera na qual se constrói Antônio. Já Freitas (2014, p. 55), em sua pesquisa de mestrado, chama a atenção para a imagem das quatro galinhas coloridas, sobrepostas em um céu azul e nuvens brancas, e a lança em queda, em tons com cores do arco-íris, "o matiz", que simboliza uma ponte entre dois mundos, o céu e a realidade da vida prosaica. A pesquisadora destaca, ainda, que a última ave está no sentido contrário à lança: "não seguindo o sentido indicado, ou seja, aquele mais próximo da Terra, do mundo real, ela se difere do restante do bando, tornando-se mais próxima do que é etéreo". Enfim, a composição da capa (parte verbal e não verbal) já estimula a imaginação convidando o leitor a buscar os sentidos construídos ao longo da obra. 
revelam que, em certa medida, cumprimos nossos objetivos. Ainda para avaliar nosso trabalho, enquanto coordenadoras e formadoras, procuramos continuamente corrigir as atividades entregues.

O grupo ficou bem dividido na escolha das atividades (primeira ou segunda opção). Apenas para citar alguns exemplos, além da leitura do livro Indez e a análise da capa, alguns optaram por construir questões sobre textos sincréticos, como a capa de uma revista, a capa do livro Preconceito linguístico, de Marcos Bagno, poemas do livro Eu me chamo Antônio, de Gabriel Pedro. De maneira geral, os trabalhos apresentados mostraram o esforço dos participantes na leitura desses textos; alguns ainda demonstraram imaturidade em relação à construção de perguntas para aplicação em sala de aula. Dessa forma, sentimos a necessidade de pensarmos outros momentos para trabalhar esses tipos de construção.

Ao final das formações que envolveram o projeto, pedimos uma avaliação escrita, a partir de duas perguntas: 1 . Em relação à formação envolvendo o eixo leitura, teça comentários sobre o(s) ponto(s) negativo(s) e o(s) pontos(s) positivo(s); 2. Há sugestões para as próximas formações? Aponte.

Nas respostas dadas para a primeira pergunta, encontramos reclamações em relação ao pouco tempo trabalhado em cada temática, o que nos fez refletir sobre o aprofundamento de algumas questões, como a análise de textos sincréticos, em outros momentos de formação. Entre os pontos positivos, a maioria destacou a possibilidade de aprender sobre os vários gêneros discursivos, literários ou não, e pensar propostas de práticas, utilizando-os. Essas respostas incentivam a continuidade de nosso trabalho, são "termômetros" para a organização das atividades do PIBID-Letras.

\section{PALAVRAS Finais}

As discussões partilhadas entre os professores universitários, os professores da educação básica e os futuros professores envolvidos no PIBID-Letras partem do princípio da relação indissociável entre ensino, pesquisa e extensão; a sequência de encontros propostos no projeto vem ao encontro disso.

As temáticas, no campo do ensino da leitura e da escrita, estão aliadas aos conhecimentos necessários para o melhor encaminhamento das aulas de Língua Portuguesa na escola, tanto por parte dos professores, quanto dos graduandos, que, participando das discussões, poderão conhecer um pouco mais da realidade vivenciada por professores da escola básica e pública. Nesse sentido, o ensino permeia 
todas as etapas do referido projeto. No caso específico apresentado neste texto, o desafio é possibilitar que as escolas envolvidas revejam alternativas para integrar a leitura/literatura nas aulas de Língua Portuguesa, possibilidade exemplificada com o trabalho em torno do livro Indez.

No que se refere à pesquisa, ela é o suporte do projeto, perpassa as leituras e as discussões (sobre aspectos teóricos e práticos) propostas nos encontros. E o caráter extensionista está marcado na presença da universidade na escola, além da vinda dos professores da escola para os encontros, com intuito de estabelecer um diálogo próximo sobre as temáticas de ensino. Nas idas às escolas, os alunos, pibidianos e petianos, desenvolveram projetos relacionados ao conteúdo das oficinas das formações ofertadas.

O que fica em relação ao projeto e em relação à importância do PIBID é a partilha/ganho de conhecimentos entre professores universitários, alunos em formação e professores da educação básica. O princípio do contínuo renovar dos conhecimentos. A dinâmica da formação continuada permite viver o postulado de Paulo Freire (2002, p. 25), que retomamos da epígrafe deste texto: "quem ensina aprende ao ensinar e quem aprende ensina ao aprender".

\section{REFERÊNCIAS}

ANTUNES, I. Aula de português: encontro e interação. São Paulo: Parábola Editorial, 2003.

BAKHTIN, M. Estética da criação verbal. Tradução de Paulo Bezerra. São Paulo: Martins Fontes, 2003 [1953].

BRASIL. Secretaria de Educação Fundamental. Parâmetros curriculares nacionais: terceiro e quarto ciclos - pluralidade cultural. / Secretaria de Educação Fundamental. - Brasília: MEC/SEF, 1998. ./CAPES. Coordenação de Aperfeiçoamento de Pessoal de nível Superior. Portaria No 46, de 11 de abril de 2016. Aprova o Regulamento do Programa Institucional de Bolsa de Iniciação à Docência - Pibid, Brasília.

BUIN, E. Aquisição da escrita: coerência e coesão. São Paulo: Contexto, 2002. . A escrita na escola. Campinas-SP: Mercado de Letras, 2013.

; BIASOTTO, M. Escrita como acontecimento: construção do humor e mudança de perspectiva como experiências. Campinas-SP: Pontes, 2016.

DISCINI, N. Comunicação nos textos. São Paulo: Contexto, 2005.

FREIRE, P. Pedagogia da Autonomia: saberes necessários à prática educativa. 21. ed. São Paulo: Paz e Terra, 2002. . A importância do ato de ler: em três artigos. 46. ed. São Paulo: Cortez, 2005.

FREITTAS, J. D. de. A infância nos entretons da terra: um estudo sobre Indez, de Bartolomeu Campos de Queirós. 2014. 102f. Dissertação (Mestrado em Letras - Estudos Literários) - Curso 
de Pós- graduação em Letras, Universidade Federal de Mato Grosso do Sul/Campus de Três Lagoas, Três Lagoas, 2014.

GUEDES, P. C. Da redação à produção textual: o ensino da escrita. São Paulo: Parábola, 2002. QUEIROZ, B. C. Indez. 9. ed. Belo Horizonte: Miguilim, 1999.

LAJOLO, M. O texto não é pretexto. In: ZILBERMAN, R. (Org.). Leitura em crise na escola: as alternativas do professor. 3. ed. Porto Alegre: Mercado Aberto, 1982. p. 51-62.

. O texto não é pretexto. Será que não é mesmo? In: ZILBERMAN, Regina; RÖSING, Tânia

M. K. (Org.). Escola e leitura: velha crise, novas alternativas. São Paulo: Global, 2009. p. 99-112.

ROJO, R. Letramentos múltiplos, escola e inclusão social. São Paulo: Parábola Editorial, 2009.

. Pedagogia dos multiletramentos: diversidade cultural e de linguagens na escola. In: ROJO,

R.; MOURA, E.(Org.). Multiletramentos na escola. São Paulo: Parábola, 2012, p. 7-31.

RUIZ, E. M. S. Como se corrige redação na escola. Campinas-SP: Mercado de Letras, 2001.

SANTOS, L. V.; RICHE, R. C.; TEIXEIRA. Análise e produção de textos. São Paulo: Contexto, 2015.

\section{SOBRE AS AUTORAS:}

Eliane Aparecida Miqueletti é graduada em Letras (Universidade Federal de Mato Grosso do Sul/Campus de Dourados), tem Mestrado em Letras (Universidade Federal de Mato Grosso do Sul/Campus de Três Lagoas) e Doutorado em Estudos da Linguagem (Universidade Estadual de Londrina). É professora da Universidade Federal da Grande Dourados. Tem experiência na área de semiótica francesa e ensino, com pesquisa nos seguintes temas: Semiótica Francesa, a construção da identidade indígena, o ensino de Língua Portuguesa e o Estágio Supervisionado Obrigatório.

E-mail: elianemiqueletti@ufgd.edu.br.

Edilaine Buin é graduada em Letras (Universidade Estadual de Campinas), tem Mestrado em Linguística (Universidade Estadual de Campinas) e Doutorado em Linguística (Universidade Estadual de Campinas). É professora/pesquisadora da Universidade Federal da Grande Dourados. Tem experiência na área de Linguística Aplicada, com pesquisa nos seguintes temas: Aquisição da Escrita, Letramentos e Formação de Professores. Atualmente, é tutora do Programa de Educação Tutorial (PET) do curso de Letras-UFGD.

E-mail: edilainebuin@ufgd.edu.br.

Recebido em 07 de agosto de 2018 e aprovado em 18 de outubro de 2018. 